\title{
EMOS reloaded: Unlock the future of education in official statistics with a new partnership with Universities
}

\author{
Monica Pratesi ${ }^{\mathrm{a}}$ and Pedro Campos ${ }^{\mathrm{b}, *}$ \\ ${ }^{a}$ University of Pisa, Pisa, Italy \\ ${ }^{\mathrm{b}}$ University of Porto, Statistics Portugal, Porto, Portugal
}

\begin{abstract}
After 12 years of EMOS experience it is time to open the discussion on the future of EMOS.
This papers briefly describes the experience from the perspective of the Universities, trying also to describe the needs and role of the NSIs, Banks and other possible actors to join the network, and unlock the future.

EMOS should reload (or evolute) to stay current and attractive. Statistical 'thinking' evolved and a major change and challenge for EMOS is to pick up this trend in its cooperation with the universities.
\end{abstract}

Keywords: Official statistics, university and education, statistical literacy, data literacy and thinking

'The only thing that is constant is change' - Heraclitus "After a time of decay comes the turning point" - The

Ching

"We delight in the beauty of the butterfly, but rarely admit the changes it has gone through to achieve that beauty."

Maya Angelou

\section{Introduction}

EMOS is a European network of University Master programs in official statistics. EMOS is currently a unique and innovative path within various courses of study already active in universities. This is its peculiarity and novelty: there is no such path in the world, and together with the Joint Statistical Programme in Survey Methods [1] it represent an example of cooperation between Universities and National Statistical Institutes and other producers of official statistics.

\footnotetext{
* Corresponding author: Pedro Campos, University of Porto, Statistics Portugal, Porto, Portugal. E-mail: pedro.campos@ine.pt.
}

The basic idea originated in Southampton in 2010, when a Group of Experts from Universities, NSIs and Eurostat started the discussion on the EMOS. For a clear description of the history of the EMOS, its actors, governance and procedures we refer to the paper by Annika Näslund [2]. The paper by Mojca Bavdaž and others, published in this special issue, gives additional hints on the EMOS network and its rationale [3].

Here we highlight that at the basis of the project there is the concept that there is a core of knowledge, skills and competences (quantifiable in ECTS and called Learning Outcomes) essential to those who aspire to be educated to work in official statistics, both in the production of data and in their analysis and dissemination and also to simply read and use and analyze data and Official Statistics. This "core" knowledge is defined after consultation, redesign, contributions and constraints by the Universities and the other Institutions involved in a process well described in the cited works [2,3].

In this paper we try to see EMOS from the perspective of the Universities already in the network and eventually ready to join it, trying also to describe the role of the NSIs, Banks and other possible actors to join the network. Section 2 describes briefly our ideas on 
the emerging needs of statistical knowledge. In the last decade there has been an evolution of official statistics following the so-called data deluge. Also in University education, topics such as Data Science, Artificial Intelligence, Data Analytics have raised interest in the education of students and in their training. In fact, statistics and statistical literacy have also evolved. Section 3 describes how EMOS is implemented in the Universities and how should it be implemented to face the challenges, summarizing also what students and Universities says on their needs. Section 4 is dedicated to the description of the needs of the National Statistical Institutes and in general of statistical agencies and authorities in National Statistical Systems and in Not Governmental Organizations (e.g. Ministries, Statistical Departments, Chambers of Commerce, Banks) in terms of competences and skills of their employees comparing them with what EMOS offers. Section 5 concludes with our findings and recommendations.

\section{Statistics and knowledge on data in the University programmes: An evolving scenario}

Today life requires understanding many complex phenomena: globalization, with international trade, value chains, consequences on employment, real incomes; environment protection, quality of life and last but not least sustainability. Glocal is the adjective relating to the connections or relationships between global and local problems, businesses, etc [4]. Moreover Sustainable Development Goals launched by United Nations are tracing an idea of progress that requires new data and statistical analysis to monitor its development and the global and local target to reach [5].

The scenario is challenging and the need for specific competences in statistics and data analysis especially in the education of new generations is clearly urgent. In addition, an integrated and articulated information system that coordinates the data and the analysis on the phenomena and is able to allow for global and local perspectives is urgent as well. At the same time, our increasing daily dependence on technologies, social media and electronic transactions is producing huge amounts of data. The data produced refer to the most varied areas of natural, economic, and social sciences. They are labelled as "big" also because of their complexity (texts, diagnostic and satellite images, signals (and can provide information on events, behaviors and relationships that a few years ago were not easily measurable.
It is clear that Universities are following these changes and preparing adequate programmes of study to prepare the students to understand and possibly guide these complex phenomena and maybe contribute to the design of the information system. However, it is not clear according to which paradigms the Statistics and Data Science could and should analyze the phenomena in order to bring benefits to the society and to everyone's life, as Melchiorre Gioia wished two centuries ago [6]. Especially for Official Statistics.

These are big challenges and they have been faced by the European Statistical System (ESS) finalizing the Trusted Smart Statistics strategy [7]. Anyhow, Universities in the EMOS network and any statistical organization (national, regional, and international) have a role of promoter of the understanding, development and good practice of statistics and official statistics.

Nothing new under the sun. The development of methods for statistical and socio-economic and demographic analysis has always been accompanied by the most modern storage and computing technologies available, which provided efficient and complex analyses of the data processed. Techniques like interaction of sources, data integration, data fusion, data mining, analysis of functional data, multivariate analysis, simulations, estimation algorithms, and so on, would not have been possible without a continuous dialogue and exchange with computer scientists. Already in the second half of the last century, there were discussions about data analysis and data driven analysis, learning by data, Data Science, and about the validity of the level of knowledge reached.

However nowadays statistical "thinking" is evolving fast as the landscape in which statistics operates is changing fast, as seen in previous paragraphs. The concept is evolving including not only traditional statistical literacy, but we need to give more space to concepts like data literacy and data awareness [8].

In our view we have evolved from statistical literacy to a more comprehensive concept named statistical thinking [9], that include also data literacy and data awareness.

Statistical literacy is the ability to understand and reason with statistics and data. Being statistically literate is sometimes taken to include having the abilities to both critically evaluate statistical material and appreciate the relevance of statistically-based approaches, including uncertainty in all the reasoning applied to all aspects of life in general or more specifically when evaluating, design, and/or produce scientific work (see the International Statistical Literacy Project by the IASE) 
Data literacy is the set of skills to collect, manage, evaluate and apply data in a critical manner [10]. Generally speaking, the term 'awareness' can be defined as "the state or condition of being aware; having knowledge; consciousness." For data awareness, we might refine this definition as "having knowledge of the data that exist on a phenomenon and an understanding of its contents.'

To think statistically is to think in distributions and probabilities (the need for statistical literacy) and also to understand the role of statistical data (data literacy and data awareness). Also data production process can generate uncertainty as it is subject to errors and misleading. Data production and data analysis should be considered within the greater machinery of generating scientific knowledge.

Official statistics agencies and statistical literacy educators have been working together in the past. See for example [17], where Statistics New Zealand, like some other NSOs, introduces a number of products designed specifically to support school statistics learning and a larger number designed for public and/or professional audiences. Statistics Education to promote statistical literacy at the University level is addressed in [18] and aspects for future research are stressed in terms of technology use, content and pedagogic approaches.

In the context of this evolving scenario, the EMOS project can play an important role in co-creating and reinforcing statistical thinking, in line with the European Data Strategy. The challenge for EMOS is to pick up this trend in its cooperation with the universities. The objective is to educate students and contribute to empower people, businesses, and organisations to make better decisions based on insights from official and nonpersonal data.

There are three aspects stemming out: i) the importance of the continuous exchange between different disciplines in university Master programmes; ii) the necessity of a pervasive statistical thinking in the university education; iii) the necessity that the "core" knowledge, competences, skills be adequate to the evolving scenario.

\section{EMOS in the Universities}

In general, we must admit that the Academy is not interested in issues related to the production of official statistical data. Already in 2015 Danny Pfeffermann noted this and cited EMOS as an example of University courses dedicated to the themes of official statistics [11].
The EMOS network builds on existing and nationally accredited Master of Science (MoS) programmes.

Very shortly: Universities can participate to a call to candidate a MoS to host the EMOS track. The 32 Master of Sciences now in the network range from MoS in Statistics, Survey methods to MoS in Economics, Finance and Data Science. The label is awarded by the European Statistical System Committee to the university Master programmes, certifying that the graduates familiarized with the system of official statistics, production models, statistical methods, and dissemination.

The title obtained by the students is not a degree in Official Statistics but a University degree labelled EMOS, certifying that in the course of study space has been given to that "core" of knowledge, able to familiarizing the student with the system of official statistics, production models, statistical methods and dissemination.

EMOS labelled Master programmes collaborate actively with the National Statistical Institutes or other producers of official statistics for relevant master thesis topics and internships in the sphere of official statistics.

This is the aim of EMOSin the scope of its cooperation with the universities. But there are new opportunities of picking up important developments where the universities are forerunners: universities are involved in European Programs, using modern online teaching tools, and are investing in laboratories. EMOS "reloaded" should make even more use of these developments coupled with eventual challenges in these type of cooperation.

There are needs and questions emerging by a pilot Focus Group conducted in few Universities already in the network and others not yet involved. ${ }^{1}$ They all knew the EMOS project. We reserve to repeat the experience enlarging it to the whole set of Universities of the network.

\subsection{Universities are involved in European Programmes}

The European programmes which are seen as related

\footnotetext{
${ }^{1}$ The Focus Group involved representatives of the University of Florence (reference person to EMOS: Prof Alessandra Petrucci), The Warsaw University of Life Science (reference person to EMOS: Prof Mariola Chrzanowska), The Universi ty of Trier (reference person to EMOS: Prof Ralf Mnnich), The University of Pamplona (Prof Lola Ugarte), The University of Leuven (Prof. Michel Meulders).
} 
to the EMOS network are the Erasmus +/Erasmus program and the Marie Curie Actions. The Erasmus + aims to improve professional skills and perspectives and modernize education and training by allowing students to undertake a period of study and training (traineeship) in the member countries of the European Union and other countries participating in the Program. The MSCA European Postdoctoral fellowships and Doctoral networks support researcher careers and foster excellence in research.

Universities have specific offices for international initiatives but they are asking for a more specific connections with the EMOS partners to support EMOS related Double degrees, Joint degrees, exchange of Professors, study visits born under the Erasmus + programme. There are initiatives for students as the Pisa-Trier Double degree and Eurostat Statistical Week, the study visit to learn more about the set-up, functioning and role of Eurostat. European cross-borders internships are a next frontier and the connection with Erasmus mobility schemes is to set up. A clear EMOS action with Universities' Job Placement Offices needs to be planned and a more specific connection with the Erasmus + initiatives as the organization of Course modules, Chairs and Centre of Excellences is welcome. The 2021-2027 Erasmus + programme places a strong focus on social inclusion, the green and digital transitions, and promoting young people's participation in democratic life. These are all themes where official statistics "core" of knowledge undoubtedly play an important role and a specific track for application on Official Statistics topics can gather the interest of Universities and offer financial support to EMOS initiatives. The EMOS project should be included in the actions under the ERASMUS + program.

Excellence in research on Official Statistics can be supported by the cooperation with Universities. A future project - maybe a dream - to reinforce the bridge between official statistics and academia is the organization of a Doctoral network supported by Marie Curie doctoral networks action. Many different types of organization can apply, from universities to Small Medium Enterprises to large commercial companies. NSIs would make a good non-academic partner but also companies and institutions operating in the data science, business intelligence (BI), machine learning (ML), artificial intelligence (AI), AI software development and banks. Accredited EMOS Doctoral Networks would give junior researchers experience of different working environments though secondments and this will facilitates interactions among future official statisticians in international settings, as well as providing transferrable skills training to improve employability and create a scientific perspective for future "European statistical thinking".

\subsection{Universities are using online teaching tools}

Due to the epidemiological emergency caused by COVID-19 and in compliance with government provisions, in-presence teaching activities in Degree Programmes of many Universities in Europe and in the world have been suspended at least up to the next fall 2020. This have caused an acceleration in the use of E-learning platforms, On-line lessons, downloading of the educational materials and any notes available. Tools used in exceptional circumstances, like webinars, online workshops have become of daily use in university life.

Universities are oriented to reinforce the offer of Massive Open Online Courses (MOOC) and are studying the opportunities offered by micro-credential systems. A MOOC is an online course that has open access and interactive participation by means of the Web. MOOCs provide participants with course materials that are normally used in a conventional education setting such as examples, lectures, videos, study materials and problem sets [19].

According to a definition by European Commission: Micro-credentials are statements that acknowledge that a person has acquired a discrete competence, i.e. knowledge, skills and/or experience in a well-defined and limited area. In a broader sense the term micro-credential generally refers to both the learning activity leading to a credential and the credential itself. The existing definitions describe different characteristics of microcredentials, such as size, purpose, categorisation (as formal or non-formal education units) and types of short courses they may encompass. Definitions are not completely clear: very often they are qualified as "digital", referring to the format of the credential, its presentation, the mode of provision or dissemination, content, or a combination of these [20].

Teaching materials to distribute using E-learning platforms are considered an essential asset by Universities. The production of teaching materials covering the Learning Outcomes of the EMOS programme is an objective of the network and the organization of them into examples, lectures, videos, populating one or more MOOC courses can be an option for the EMOS network future activity. The EMOS webinar series can be seen as a step in this direction. Students can consult 
the study materials of webinars, available also as podcasts, anywhere and anytime. Organizing the range of EMOS content: lessons, images, audio and video files, and links to Web resources in the Eurostat Education Corner would facilitate the usage by the Universities of the network.

There are problems to solve. The issue of educational credential obtained participating into a MOOC is open and worth to have a specific address by the Universities of the network. Every University of the EMOS network can have diverse requirements and solutions in the Bologna Process (Bologna process, 2020). Moreover the definition of EMOS micro-credentials is a challenge: it can be seen as a mean to respond to learners' needs for upskilling and reskilling, working in cooperation with ESTP programme as described by the authors of [3]. Also the stackability of micro-credentials is an issue. Referring to the definition formulated by the European Consortium of Innovative Universities (ECIU) we can say that: "certification of learning" can accumulate into a larger credential or degree, and be part of a portfolio that demonstrates individuals' proof of learning, or have a value in itself [21]

\subsection{Universities are investing in Laboratories for data analysis}

Data analysis is a process that relies on methods and techniques to taking raw data, mining for insights that are relevant to the analysis, and exploiting this information to take actions.

This process is taught today in many University programmes. They all ask for an easier access to real-life data.

Universities offering EMOS Master degrees already collaborate actively with the national statistical institutes to reduce the gap between theory and practice. In this direction pertinent topics for Master thesis, internship in the area of official statistic are strongly encouraged by Universities of the network.

During the internship in NSIs students can have the opportunity to access Microdata files. These are collections of elementary (raw) data. National Statistical Institutes indeed can organize and maintain Laboratories for Elementary Data Analysis (e.g. Istat Laboratorio ADELE). They are a "safe" environment in which researchers from universities or research institutions or bodies under the privacy law can apply to processing of personal data for statistical and scientific purposes applies. In this safe environment researchers and students may conduct statistical analyses that require the use of elementary data, where information already available with other tools is not sufficient. EMOS students often access to microdata by such Laboratories.

However Universities are expecting that the EMOS network provides facilities to access case-study based on real data or on simulated data. Examples are a Living Library of accessible microdata and scientific materials EMOS-related and a section for EMOS students in the Big Data Sandbox or similar projects created in the context of the UNECE Big Data project.

Living Library of accessible microdata: EMOS could offer authoritative guidance to the best online libraries and public data archives, scientific journals, e-books, and databases on EMOS topics in Europe, selected by a multidisciplinary panel of experts, available to students of Universities of the network, all with just a click.

The Sandbox is a shared platform for users from various international statistical organizations to access remotely and collaborate on shared methodologies and datasets [22]. The platform itself is composed of a set of 5 servers which enable the reliable storage of up to $56 \mathrm{~TB}$ of data and high performance concurrent processing of this data across $80 \mathrm{CPU}$ cores. Users access a unified login portal connected to the Internet via a high bandwidth network connection. An EMOS cooperation could design an EMOS Student Corner in this initiative allowing students to access to a high tech internship performing modern statistical analysis.

Summarizing, the EMOS should evolve having a tighter connection with the Universities: building channels of communications with Job placement offices, investing in Erasmus + and Marie Curie initiatives promoting specific calls on the topics of the EMOS, studying the MOOC/micro-credentials opportunities with the universities, investing in joint Laboratories. Working in this direction the idea is that the EMOS reloaded would provide access to a trusted, virtual, federated environment to store, share, process and re-use research digital objects useful to EMOS students and teachers (like publications, data, and software) as the European Open Science Cloud, in line with the European Data Strategy.

\section{EMOS and the agencies' needs}

The EMOS network is now working in the field of education and cultural promotion of Official statistics more than in the field of specific training of future or present officers. Anyway, an essential part of the "core" knowledge is an internship in a statistical agency recog- 
nized by the European Statistical System. The topics of the internship are generally decided by tutors from the statistical agency and the University staff. It is desirable that the Master thesis is linked to the internship.

This is good as it is, as noted in other contributions [3] and it is a way to introduce the students in activities of a statistical agency. Obviously, it can be seen as a limitation and in a recent survey on the EMOS students $^{2}$ the hint from their side is to open to the possibility of offering internships also to banks and other Institutions/agencies involved in the production and in the analysis of official data.

As the topic of the internship is the result of a "negotiation" between the University supervisor and the internal tutor of the hosting institution or agency it is important to gather the ideas on the needs of the institution hosting the student. In this section we try to understand and comment on these general needs underlying the "core" knowledge required and the emerging areas of interest.

However an important insight is that on the competences of the employees of a National Statistical Institute to understand if and at what extent these can be covered by the EMOS project.

In a recent experiment conducted at the Italian Statistical Institute a team of experts in human resources [12] have collected a large range of technical capabilities, knowledge, and expertise - not only statistical ones needed to work in a national institute of statistics. The experts have defined six thematic areas: statistics, information technology, administrative, communication, organization, and foreign languages. Each area is subdivided into several subareas and each subarea provides a list of individual competencies. Overall, the classification consists of 29 subareas and 276 skills. It also provides a self-assessment scale of the mastery level structured in five modes: 0-none, 1-limited, 2-discret, 3-advanced, 4-expert.

For each of the thematic areas the skills were classified into owned by personnel, acted by personnel, expected by the Institute.

Not considering the administrative, organization and foreign language areas, the focus of EMOS is on statistics, information technology and communication.

\footnotetext{
${ }^{2}$ The survey on occupation, carried out in the period May 2016May 2017 by Istat for the implementation of the competence system, has been based on the coding of the daily working activities. The data collection started inviting personnel to codify own occupation focusing on the main working activities. The respondents described their tasks and then could use different search engine in order to find the best code for their work.
}

However, in the long run, trust in official statistics can only be maintained based on a continual striving for the best quality, with leadership based on profound knowledge of the business and with customer orientation as the supreme orientation. This implies that statistical products must meet the expectations of users in their design, production, and communication [13]. In the following, we focus on four aspects that we think are currently the most important in terms of official statistic needs, shared also by statistical agencies of national statistical systems: Administrative sources, Big Data/Smart Statistics, Statistical Confidentiality, and Social Issues.

\subsection{Administrative data}

Important goals for official statistics are the reduction of costs, reduced response burden, and the improvement of data coverage and availability [14]. Often, the results of sample surveys pertaining to population sub-groups cannot be presented due to unacceptably large sampling error. So, we need to improve the quality and efficiency across the entire statistical production system, using administrative data sources. Data from administrative sources needs to be adapted and processed to make it suitable for statistical compilation: transform administrative entities into statistical units and transform administrative variables into statistical variables.

Of course, this process is not straightforward, and we need a process of Data Governance, i.e. an authority to match data from different sources and ensure accountability mechanisms for data quality and the protection of data privacy and confidentiality.

\subsection{Big data/smart statistics}

The development of big data is set to be a significant disruptive innovation in the production of official statistics offering a range of opportunities, challenges, and risks to the work of National Statistical Institutions (NSIs) [15]. In the last few years, NSI's have dedicated a part of their time to analyze possible alternative sources to produce official statistics, namely those coming from Big Data. Included in the set of possible sources, are those from which the information is collected by sensors, or by digital means, GPS, Satellite, Mobile Phones, etc.

New statistical opportunities and production models deriving from digitalization of societies and big data allow NSI's to prepare the future for trusted smart statistics. Smart Statistics can be seen as the future extended 
Table 1

Matching between the required EMOS learning outcomes, and the current important topics

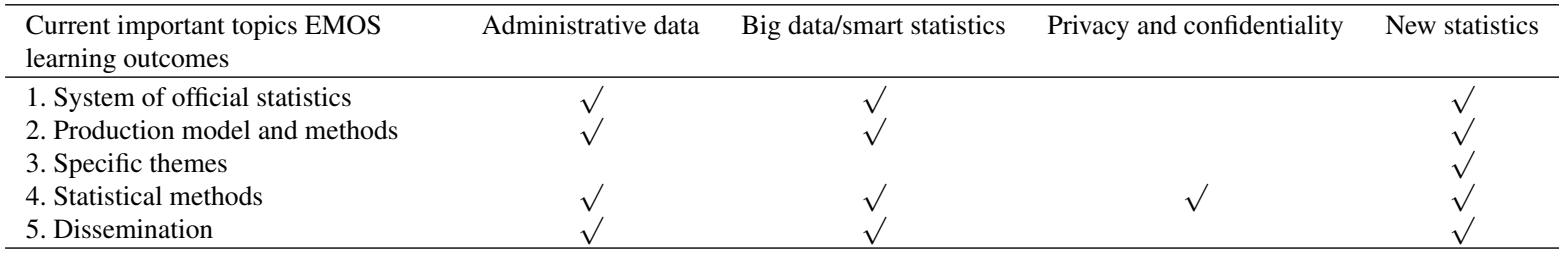

role of official statistics in a world impregnated with smart technologies. Smart technologies involve realtime, automated, interactive technologies that optimize the physical operation of appliances and consumer devices. Statistics themselves would then be transformed into a smart technology embedded in smart systems that would transform "data" to "information". We can see Smart statistics

In the ESSNet Big Data initiative [16] the several work packages included the following topics, that may constitute important sources for some specific outputs:

- Online job vacancies.

- Enterprise characteristics.

- Smart energy.

- Tracking ships.

- Financial transactions data (FTD).

- Earth observation.

- Mobile networks data.

- Innovative tourism statistics.

- Methodology and quality.

Take the example of Financial transaction data (FTD) that potentially contain all financial transactions in a country and can potentially enrich official statistics in various fields such as economic statistics and business structure statistics. In a society in continuous process of digitization where new payment solutions emerge as an option to cash and where the internet enables easier trading, FTD are a natural data source for statistics monitoring the economic activity.

The statistical potential of the FTD sources already being available or potentially being available, is already being taken in consideration in several countries.

Of course, we are still in an early stage in some cases where it is important to assess the statistical potential of these data sources. This may be for improving the existing quality or for quality evaluations of some currently produced statistics, or it may be for a completely new portfolio of statistical products

Therefore, empirical investigations should underpin conclusions about potential and implementing statistics based on such data sources.

\subsection{Statistical confidentiality}

Statistical confidentiality is a fundamental principle of official statistics enshrined in the Treaty and in the European statistics Code of Practice. With the use of new potential sources for the production of Official Statistics, people are ever more concerned about the protection of individual data under the GPDR (General Data Protection Regulation). Harmonisation of principles and guidelines as regards protection of confidential data is the obligation of Eurostat and national statistical authorities in the European Statistical System.

\subsection{Focus on (new) issues}

Some topics will continue to be important or will become even more important for strong scientific policy and statistical impact. Sensitive topics, such as racism, gender discrimination, or collaborative economy are examples of such topics, where we also include:

- Migration/ethnicity issues.

- Creative industries.

- Intangible capital (COIVEST, INNOVRIVE, SPINTAN)

- Global value chain (WIOD).

- Circular economy/waste.

Therefore, it is important to make a matching between the needs of the NSI's and the Offer from the Universities. EMOS learning outcomes include System of Official Statistics, Production model and methods (that covers quality issues, sources, architectures, GSBPM model), Specific Statistical Themes (such as economic, Finance, Population, Environment, Energy ... ) and Statistical Methods (sampling, index numbers, ... ), and Dissemination.

Table 1 shows a cross tabulation between the required EMOS learning outcomes, and the ones we have identified above as the currently most important official statistical needs.

In addition to these current needs, there have been discussions around other topics considered important issues in the future official statistics, such as data scout- 
ing and the role of data stewardship. Data stewardship is the careful, responsible, and ethical management and use of data. For that purpose, UNECE [23] recently created a Task Force is to clarify the terms related to data stewardship and public data governance, and the tasks of NSOs that this may include in different settings. The goal is to serve as a basis for developing guidance, in a later stage, on the role of NSOs in the new data ecosystem.

Another important topic that is somewhat hidden in EMOS curricula is computing with data. Nowadays, computing with data is a core activity in statistical offices. The majority of EMOS programs already cover programming with $\mathrm{R}$ and Python for data science purposes. However, as stated by Mark van der Loo in another paper in this special issue, the area of computing often falls between the two stools of data analysts and IT developers. Mark proposes the role of Research Software Engineer (RSE) who could write a generic methodological software library that can be used across different production processes.

\section{Conclusions}

In his paper Pfeffermann identified the "core" topics of interest related to the production of official statistics as those contained in courses as Survey sampling, Seasonal adjustment (SA) and trend estimation, and National accounts. This because it is reasonable that the concepts taught in these courses are required in the background of an officer working in a statistical agency.

Today the "core" set defined by EMOS is larger involving also the system of official statistics, production models, including the enterprise architecture concepts applied to official statistics and treatment of big data, smart statistics, Statistical confidentiality, Administrative data and new social topics, but also time series analyses, seasonal adjustment, outlier treatment, index theory, multivariate statistics, econometrics, spatial statistics, knowing the concepts of metadata, paradata, data integration, critical capacity of framing analysis of statistical data.

A very large core set that requires an interdisciplinary approach and the support of the ESS to the Universities, together with a tight cooperation of researchers from statistical agencies and other data producers in teaching courses. Statistical thinking is evolved and still evolving, with a focus on data awareness and data literacy, and on the uncertainties and measurement errors emerging in the analysis of modern data sources.
But knowing this is not enough to design a university programme. Universities are asking for an Institutional support by the ESS to enlarge the sets of Master programmes eligible to host the EMOS track. This can be done using the already existing Erasmus and H2020 programmes, dedicating calls to the topics relevant to the education for official statistics and statistics in general; providing teaching materials and training for teachers and professors; also encouraging research and teaching innovation in partnership with National Statistical Institutes, Banks, and other statistical agencies, especially encouraging data laboratories and "big data sand-boxes".

All in all EMOS should invest more in cooperation with Universities, through the involvement in European Programs. It is a matter of fact that collaboration among universities is a strength of the EMOS project. This must evolve and be reinforced also in view of the Alliances for innovation as supported by the Erasmus + programme. Europe's innovation capacity can be boosted through stronger cooperation and knowledge flow among universities, official statistical agencies, businesses and the broader socio-economic environment, including research.

Statistics and statistical thinking is evolving and calls for designing European core curricula and training programmes on official statistics, building on the EMOS experience and reloading the EMOS project.

\section{Disclaimer}

The views and opinions of authors expressed herein do not necessarily state or reflect those of the employing organisations of the authors. Reproduction and translation for non-commercial purposes are authorised, provided the source is acknowledged.

\section{References}

[1] Clark CZF, Groves RM. The joint program in survey methodology: A government partnership for an academic program. 2002.

[2] Näslund A. EMOS - Towards a unified training of European public statisticians. Statistique et Societé. 2020; 8 .

[3] Navarre E, Lehtimäki H, Zwick M, Bavdaž M. Education in official statistics: A common challenge of providers of official statistics and universities. Statistical Journal of the IAOS. 2021; p. 1-7. doi: 10.3233/SJI-210837.

[4] Rajan R. The third pillar: How markets and the state leave the community behind. EGEA Bocconi Editore. 2019

[5] Mazzuccato M. Mission economy: A moonshot guide to changing capitalism. Keynote speech at the 2021 NTTS Conference. 2021 
[6] Gioia M. Filosofia della statistica. Nabu Press. 1826.

[7] Wirthmann A. Trusted smart statistics: A reflection on the future of (Official) Statistics. 2018 European Conference in Official Statistics Kraków (Poland). 2018.

[8] MacFeely S. The continuing evolution of official statistics: Some challenges and opportunities. Journal of Official Statistics. 2016; 32: 789-810.

[9] Steel EA, Liermann M, Guttorp P. Beyond calculations: A course in statistical thinking. The American Statistician. 2019; 73(sup1): 392-401. doi: 10.1080/00031305.2018.1505657.

[10] Shüller K. Future skills: A framework for data literacy. HFD Working Paper. 2020

[11] Pfeffermann D. Journal of Survey Statistics and Methodology. 2015; 3: 425-483.

[12] Ottaiano A, Scalisi P. Setting up a competence system at Istat, Economic commission for europe conference of european statisticians. Workshop on Implementing Efficiencies and Quality of Output, Geneva. 2017.

[13] Press I. Why should there still be a need for elaborate official statistics in the future? 2020. Available from: https://officialstatistics.com/news-blog/why-should-there-still-be-needelaborate-official-statistics-future.

[14] Division/DESA US. Use of administrative data for official statistics: The global perspective; Available from: https://unstats.un.org/sdgs/files/meetings/sdg-inter-workshop-june2018/Day2_Session3_Adm\%20Data_UNSD.pdf.

[15] Kitchin R. Big data and official statistics: Opportunities, challenges and Risks. Statistical Journal of the International Association of Official Statistics. 2015; 31: 471-481.

[16] Eurostat. ESS Net Big Data. 2021; Available from: https://ec. europa.eu/eurostat/cros/content/essnet-big-data-1_en\#General_objectives.
[17] Sharleen F, Mike C, Nathaniel P, Paul B, Maxine P. Official Statistics and statistical literacy: They need each other. Statistical Journal of the IAOS. 2011; 27(3,4): 113-128. doi: 10.3233/SJI-2011-0729.

[18] Nikiforidou Z, Lekka A, Pange J. Statistical literacy at university level: The current trends. Procedia - Social and Behavioral Sciences. 2010; 9: 795-799. doi: 10.1016/j.sbspro.2010.12. 236.

[19] European MOOC Consortium. the Common Microcredential Framework. 2019; Available from: https://eadtu.eu/documents/News/Press_release_European_MOOC_Consortium_ launches_a_Common_Microcredential_Framework.pdf.

[20] European project MICROBOL, Bologna Process. Draft 5 of the Rome Ministerial Communiqué. 2020; Available from: http://ehea.info/Upload/BFUG_HR_UA_71_9_Draft_ 5_Rome_Communique.pdf.

[21] ECIU. Towards a European micro-credential initiative 2020; Available from: https://assets-global.website-files.com/ 562fb917aa38ca2e349b422e/5e8f1274009e48f02b9cd81a ECIU\%20University\%20Towards\%20a\%20European\%20 Microcredentials\%20Initiative\%202020_fina....pdf.

[22] Steven Vale UNECE. UNECE Big Data Work. 2014; Available from: https://unece.org/fileadmin/DAM/stats/documents/ece/ ces/ge.44/2015/mtg1/S4-3_UNECE__Vale_P.pdf.

[23] UNECE - United Nations Economic Commission for Europe, Conference of European Statisticians. Terms of reference for the task force on data stewardship. 2020; Available from: https://unece.org/sites/default/files/2021-02/04_Data\% 20stewardship\%20TOR_appr.pdf. 